\title{
BOEKBESPREKING: \\ Concubines en Courtisanes
}

Nog één keer wilde Ferry Bertholet een boek maken over Chinese erotische kunst, waarvan hij de belangrijkste collectie wereldwijd heeft bijeengebracht. Bertholet maakte een compilatie van zijn objecten en schilderingen die merendeels zijn vervaardigd vanaf de late Ming-dynastie (1368-1644) tot en met de bloei van Shanghai aan het begin van de $20^{\circ}$ eeuw. Concubines en Courtisanes moest een visueel spektakel worden met de mooiste voorbeelden. Met deze publicatie is Bertholet hierin geslaagd.

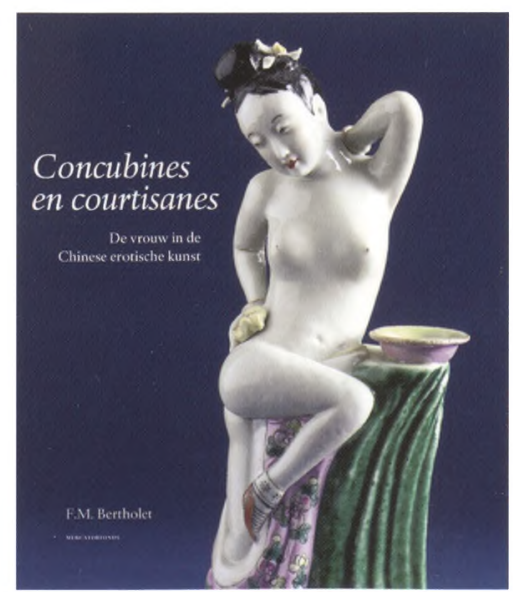

Cover Nederlandstalige uitgave. Meisje dat zichzelf wast (detail), porselein, laat$19^{\mathrm{e}}$ eeuw, h. $18 \mathrm{~cm}$., Collectie Bertholet, foto: Michiel Elsevier Stokmans.

Het rijk gedocumenteerde boek is in twee delen te splitsen, een thematisch historisch overzicht en een rangschikking naar medium. In beide delen wordt het onderwerp erotiek en de rol van de vrouw in de Chinese maatschappij van meerdere kanten belicht, zowel in de tekst als in het kwalitatief hoogwaardige beeldmateriaal.

In het eerste deel van Concubines en Courtisanes wordt de lezer Chinese cultuurgeschiedenis en filosofie bijgebracht, waarbij steeds de vrouw en erotiek centraal staan. Zo lezen we over achtergronden van het confucianisme, taoïsme en boeddhisme in relatie tot deze onderwerpen, maar ook over de geschiedenis van de 'gouden lotus', de gebonden voet. In China is betaalde liefde van oudsher populair. Het fenomeen was op een goed moment zelfs onderdeel van het officiële staatsbestel. Er was sprake van een grote variëteit van courtisanes en prostituees in verschillende klassen van hoog tot laag. Dat het in deze wereld niet altijd rozengeur en maneschijn was, laat zich raden.

Het tweede deel, 'Kunst', geeft het verhaal van de Chinese erotische kunst in beeld en tekst. Alle mogelijke media uit Bertbolets verzameling 4 komen aan $1: 47 \mathrm{Am}$ bod: fraaie snijwerken in ivoor, zogenaamde doctor's ladies, ${ }^{1}$ porselëinen ñee access 
Gelatinezilverdruk (detail), c. 1910. Bordelen kochten vaak hun meisjes, waaronder veel wezen, op jonge leeftijd. Collectie Bertholet. Foto: Michiel Elsevier Stokmans.

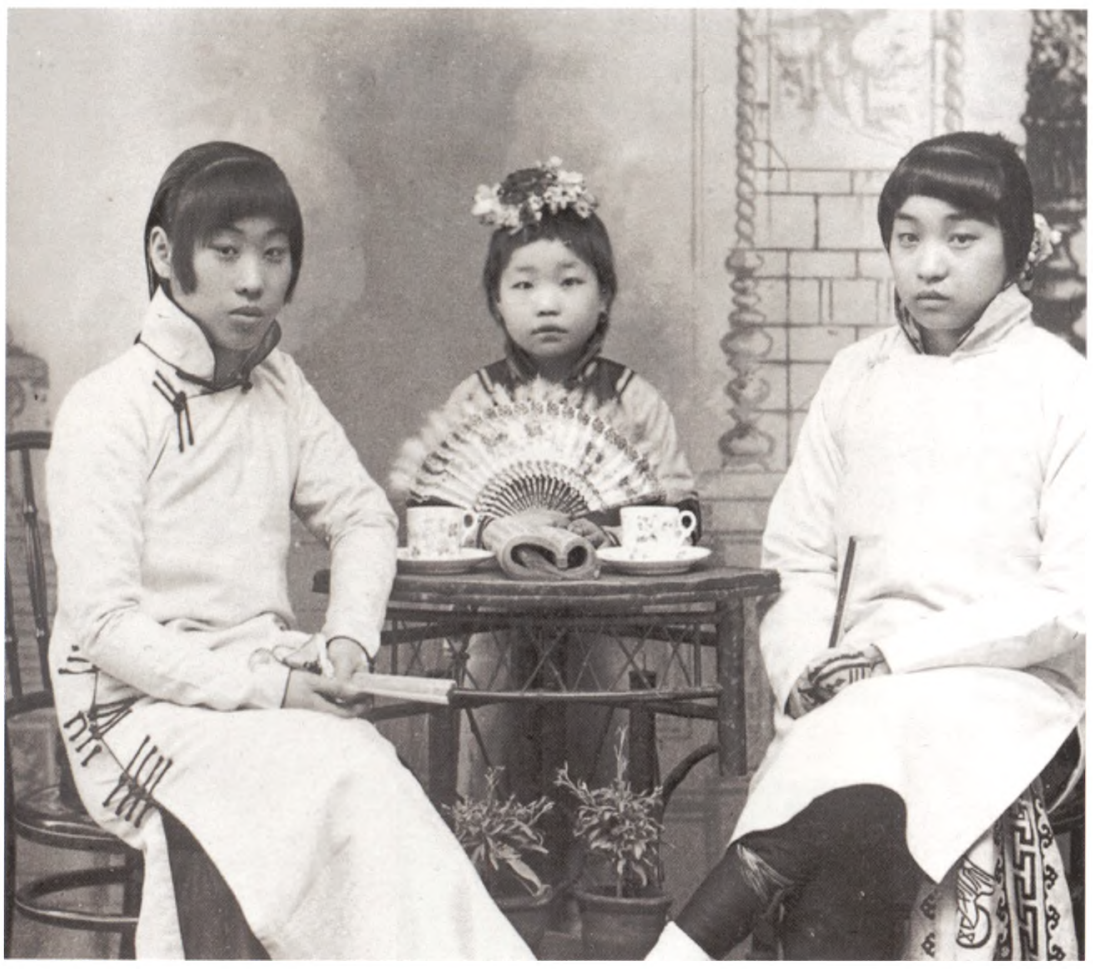

figuurtjes, snuifflesjes, lakwerk, inlegdozen, schilderingen op mergpapier, schilderijen achter glas, olieverf- en waterverfschilderingen op papier en zijde, porselein, gouaches, kalenderposters, waaiers en schoentjes. Zonder uitzondering wordt het liefdesspel op alle schilderingen kleurrijk en expliciet getoond, liefdevol, verleidelijk, fantasierijk en harmonieus. Daarentegen geven de tekst en de geposeerde zwart-wit foto's een ander beeld. De foto's zijn gemaakt in de periode 1860-1930. De streng kijkende madames en de $19^{\mathrm{c}}$ - en $20^{\mathrm{e}}$-eeuwse bordelen met hun bewoners en mannelijke bezoekers helpen de lezer om zich een beeld te vormen van de werkelijkheid.

In Concubines en Courtisanes wordt een verband gelegd tussen de geïdealiseerde beelden die we kennen van de Chinese erotische kunst en de contrasterende niet altijd zo florissante werkelijkheid. Er is overduidelijk sprake van een discrepantie op dit vlak.

De geraadpleegde literatuur is divers en uitgebreid en schakeert van populaire tentoonstellingscatalogi tot en met gezaghebbende wetenschappelijke werken. Bertholet is duidelijk op zoek geweest naar degelijke bronnen en heeft serieus geprobeerd er een leesbaar boek voor een breed publiek van te maken. De auteur hoopt van harte 'dat degenen die besluiten om het boek aan te schaffen niet alleen de mooie plaatjes zullen bekijken, maar het boek ook gaan lezen'.

Ferry M. Bertholet (VVAK-lid) is beeldend kunstenaar, schrijver en sinds 30 jaar verzamelaar van onder andere Chinese erotische kunst. Eerder verschenen boeken van zijn hand: Dreams of Spring (1997), Gardens of Pleasure (2003), Liefde en Lentebloesems (2004), Le palais du printemps (2006) en Opium, Kunst en Geschiedenis van eenWVerloren Ritueel (2007)26/2023 01:21:47AM 
Erotische (verborgen) achterzijde van achterglasschildering, $19^{e}$ eeuw, h. 39,5 cm., b. $30 \mathrm{~cm}$. Collectie Bertholet. Foto: Michiel Elsevier Stokmans.

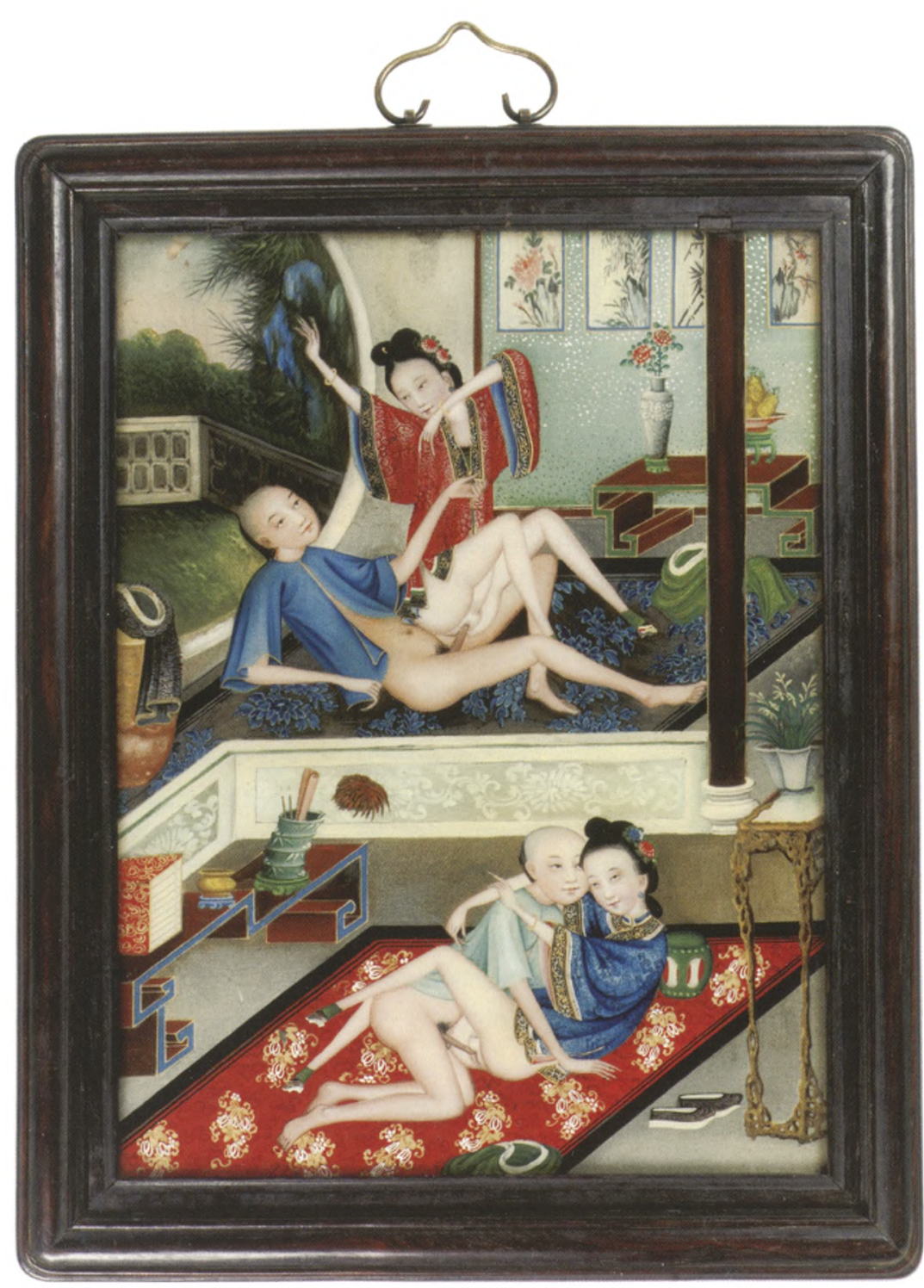

- Ferry M. Bertholet

Concubines en Courtisanes: De Vrouw in de Chinese Erotische Kunst.

Brussel, 2010

208 pagina's, 200 illustraties, hardcover met stofomslag.

Concubines en Courtisanes is te koop via ww.mercatorfonds.be, $€ 49,95$.

ISBN 978-90-7163-922-3 (Nederlandstalig), 978-90-6153-923-0 (Franstalig), 978-906153-924-7 (Engelstalig)

\section{Noot}

1. Doctor's ladies, bekend uit de Ming- en Qing-dynastieën, zijn figuurtjes van (bijna) naakte vrouwenlichamen die werden gebruikt door de traditionele Chinese mannelijke artsen bij een vrouwelijke patiënt, die op het figuurtje de plek van haar ongemak kon aangeven, zonder haar lichaam te hoeventonen. from Brill.com04/26/2023 01:21:47AM 